\title{
Revista Científica General José María Córdova
}

(Revista colombiana de estudios militares y estratégicos)

Bogotá D.C., Colombia

ISSN 1900-6586 (impreso), 2500-7645 (en línea)

Web oficial: https://www.revistacientificaesmic.com

\section{Editorial: Hacia la consolidación de la Revista colombiana de estudios militares y estratégicos}

\author{
Andres Eduardo Fernandez-Osorio \\ https://orcid.org/0000-0003-0643-0258 \\ andres.fernandez@esmic.edu.co \\ Universidad de Barcelona, España \\ Jesús Alberto Suárez Pineda \\ https://orcid.org/0000-0002-1155-3175 \\ revistacientifica@esmic.edu.co \\ Escuela Militar de Cadetes “General José María Córdova”, Bogotá, Colombia
}

Citación: Fernandez-Osorio, A. \& Suarez Pineda, J. (2019). Editorial: Hacia la consolidación de la Revista colombiana de estudios militares y estratégicos. Revista Cientifica General José María Córdova, 17(25), 1-2. DOI: http://dx.doi.org/10.21830/19006586.410

Publicado en línea: 1 de enero de 2019

Los artículos publicados por la Revista Científica General José Maria Córdova son de acceso abierto bajo una licencia Creative Commons: Atribución - No Comercial - Sin Derivados.

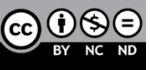

Para enviar un artículo:

https://www.revistacientificaesmic.com/index.php/esmic/about/submissions

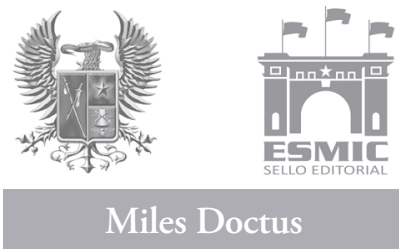




\title{
Editorial: Hacia la consolidación de la Revista colombiana de estudios militares y estratégicos
}

\section{Editorial: Towards the consolidation of the Colombian Journal of Military and Strategic Studies}

\author{
Andres Eduardo Fernandez-Osorio \\ Universidad de Barcelona, España \\ Jesús A. Suarez Pineda \\ Escuela Militar de Cadetes “General José María Córdova”, Bogotá, Colombia
}

Parte de la esencia de las publicaciones académicas consiste en evolucionar a la par con los avances de sus áreas de conocimiento. Esto garantiza que sus lectores obtengan información científica vigente y de calidad, que desafíe paradigmas y enriquezca el debate intelectual, en especial, cuando su temática se nutre de aportes interdisciplinarios, como es el caso de los estudios militares y estratégicos.

Este ha sido el camino recorrido por la Revista Cientifica General José María Córdova desde su creación, en el año 2000, tras el cual ha llegado a consolidar 17 volúmenes de contenidos académicos y científicos que dan testimonio de una trasformación positiva y permanente como Revista colombiana de estudios militares y estratégicos. En efecto, la Revista se adaptado con éxito a las dinámicas propias de esta área interdisciplinar del conocimiento, en la que se exploran perspectivas teóricas y prácticas innovadoras en cuanto al estudio del poder y su aplicación legítima en la defensa de los intereses nacionales. No obstante, la Revista está lejos de haber adoptado solamente una actitud pasiva frente a los requerimientos del área disciplinar en la que se inscribe; por el contrario, la publicación insignia de la Escuela Militar de Cadetes "General José María Córdova" ha buscado sin descanso aportar a la construcción de una cultura estratégica, de forma que más allá de contar con un espacio para publicar, se ha logrado moldear un campo riguroso de sana discusión y debate. Solo de esta manera es posible el crecimiento de una disciplina trans-

Contacto: Andres E. Fernandez-Osorio \ andres.fernandez@esmic.edu.co 
versal a los intereses de un Estado democrático, fundado en la defensa y la seguridad de todos sus integrantes, así como en las buenas relaciones con otras naciones.

Para favorecer esta construcción disciplinar, la Revista, con el respaldo de su Comité Editorial y del Sello Editorial ESMIC, se ha esforzado de manera continua para acogerse a los más altos estándares de calidad y gestión editorial, lo que le permite acercarse cada vez más a la visión de ser una publicación interdisciplinar líder en la región de Latinoamérica y el Caribe. Sin duda, parte importante del cumplimiento de estos lineamientos de excelencia ha sido el robustecimiento de su política editorial mediante la definición de las áreas de estudio en las que convergen perspectivas académicas y experiencias profesionales clave para el fortalecimiento del pensamiento estratégico, la optimización de la administración pública, la estabilidad de la democracia y a la defensa de los derechos humanos. Dichas áreas o ejes temáticos son las siguientes - los cuales están alimentados por las disciplinas descritas entre paréntesis—: 1) Educación y doctrina (ciencias militares); 2) Política y estrategia (ciencia política); 3) Seguridad y defensa (relaciones internacionales); 4) Justicia y derechos humanos (derecho); 5) Fuerzas Armadas y sociedad (historia y geografía); 6) Inteligencia y logística (administración); y 7) Industria y tecnología (economía).

Los contendidos de la Revista, en consecuencia, están enmarcados en estos siete ejes temáticos, como puede evidenciarse en los diez artículos publicados en este número, producidos por autores interdisciplinares provenientes de distintos países de la región, quienes aportan su conocimiento y perspectivas a la construcción de un debate académico, crítico pero propositivo, y respetuoso de las particularidades nacionales. De esta forma, la Revista abarca cada vez más un público amplio, que incluye decisores políticos, miembros de las Fuerzas Armadas, servidores públicos, profesionales, docentes, investigadores y estudiantes de ciencias sociales y de otras áreas del conocimiento, interesados en el pensamiento y la cultura estratégica. 